\title{
POESÍA Y DISCURSO
}

1. Introducción. En el estudio de las relaciones entre poesía y significado pueden encontrarse tres grandes vertientes: en primer lugar, la que sostiene Jakobson y que tiene como una de sus características el establecimiento de una separación entre los discursos poéticos y los demás tipos de discurso -sobre todo, los referenciales- dentro del conjunto de los sistemas de significación. Esta posición, que también está sustentada por investigadores como Lotman, no es, sin embargo, absoluta, puesto que la idea de autonomía del texto poético y de su efecto unitario de sentido, coexiste con la idea de una interrelación de la función poética con las demás funciones en el interior de la obra literaria. Esta coexistencia es el origen del postulado de Jakobson acerca de que los textos literarios sean "referencialmente ambiguos"; y ello por dos razones: en primer lugar, porque son autónomos y no se refieren directamente a tal o cual situación o aspecto de la realidad, pero, en segundo lugar, porque no cortan del todo con los clemás sistemas y funciones, incluso con las circunstancias externas de esa realidad.

La segunda gran vertiente impugna las posiciones sosteniclas en la primera ya que, de acuerdo con ella, Ios textos poéticos no pueden separarse tajantemente de los demás discursos producidos en el todo social puesto que están sujetos a las mismas determinaciones sociales y se construyen de acuerdo con las mismas reglas. Si se postulan ciertas particularidades para los textos poéticos o si se estudian como un tipo especial de discurso, este estudio tendrá que estar subordinado a las reglas generales del discurso. Como consecuencia de esta posición, la cualidad específica de los hechos literarios (la literariedad) se define ya no en términos de las propiedades de los textos sino en términos del funcionamiento de ciertos textos reconocidos como literarios por una determinada sociedad. ${ }^{1}$

I Jakobson, sin embargo, no está ausente de este segunda vertiente 
La tercera vertiente considera los textos literarios como mecanismos en los cuales coexiste el discurso (o más bien, lo discursivo) con su opuesto, con lo que llamaremos el antidiscurso; con ello discute la idea de efecto de la unidad del texto poético. Este enfoque recoge de cierto modo la idea, sostenida por los teóricos del segundo grupo, de la imposibilidad de separar los textos literarios de los mecanismos generales de producción de significación.

Este último enfoque es el que, descle nuestra perspectiva, nos parece el más fructífero, ya que también puede advertirse en la práctica de algunos poetas contemporáneos, como lo veremos en la última parte. Antes presentaremos los planteamientos teóricos de estas tres vertientes acerca de la concepción de las relaciones entre poesía y significado $y$, en consecuencia, sobre el funcionamiento de la poesía dentro de la totalidad de las prácticas sociales productoras de significación.

2. Planteamienlo del problema. Para ubicar el espacio de problemas utilizaremos las ideas de dos pensadores cuyo objeto central de reflexión no es la poesía; se trata de Claude Lévi-Strauss y Jean Baudrillard. Sus posiciones son diametralmente opuestas ya que el primero concibe la poesía como un proceso significante, mientras que para el. segundo la poesía no significa.

Para Lévi-Strauss, los textos poéticos son procesos productores de sentido; por lo tanto, la poesía no puede separarse del estudio del lenguaje. El arte en general y la poesía en particular, dice, pueden concebirse como lenguajes siempre y cuando se establezca su diferencia con las produccio-

ya que afirma qua si el lingüista trata de describir un poema, tienen que preocuparle los problemas semánticos en todos los niveles del lenguaje pues, “la significación del poema no presenta más que una parte integrante del todo, y nos preguntamos por qué el crítico cree ver en el análisis semántico de un enunciado poético una transgresión del acercamiento lingüístico. Si el poema plantea cuestiones que sobrepasan su factura verbal, entramos -y la ciencia del lenguaje nos da cantidad de cjemplos- en un circulo concéntrico más amplio, el de la semiótica, del cual la lingǘstica no es más que parte esencial" (Jakobson 1973, p. 486). 
nes del lenguaje natural. Esa diferencia está en que los signos del lenguaje natural no guardan relaciones materiales con aquello que significan; es decir, se distinguen claramente de las cosas u objetos del mundo. El arte, por su lado, estaría a medio camino entre el lenguaje el objeto. La relación entre poesía y lenguaje o entre poesia y significación es, para Lévi-Strauss, más estrecha, pues el material de la primera son las palabras.

Surge entonces la pregunta sobre el lugar de la poesía frente a los demás sistemas de significación. Si el arte, responde Lévi-Strauss, está a la mitad entre el objeto y el lenguaje, la poesía está a medio camino entre el lenguaje y el arte: el lenguaje es el "objeto" del poeta, su materia prima, y "es esta materia prima la que se propone significar, no exactamente las ideas o los conceptos que podemos tratar de transmitir por el discurso, sino esos grandes objetos lingïísticos que constituyen conjuntos o trozos de discurso" (Lévi-Strauss 1968, p. 99). En esas circunstancias el poeta puede asumir dos actitudes frente al lenguaje: o añadir a la expresión lingüística dimensiones nuevas, como hace la poesía tradicional, o proceder por "desintegración lingüística", como Rimbaud. En ambos casos toma al lenguaje por objeto para añadir o extraer una significación suplementaria. Sería inconcebible un sistema artístico o poético - concluye Lévi-Strauss- que pretendiera significar más allá o fuera de los lenguajes existentes.

Para Baudrillard la poesía destruye o disuelve todo discurso entendido como proceso de significación; para él el discurso de la poesía no significa nada. Su argumentación se basa en los estudios de Saussure sobre los anagramas, en los que "destaca la forma antagonista de un Ienguaje sin expresión más allá de las leyes de los axiomas y de las finalidades que le asigna la lingüística; la forma de una operación simbólica del lenguaje, es decir, no de una operación estructural de representación a través de los signos, sino justamente a la inversa, de desconstrucción del signo y de la representación" (Baudrillard 1980, p. 221). Si los lingüistas, psicólogos, estudiosos de la literatura y los poetas han buscado el secreto del placer estético en la riqueza del sig- 
nificado, puede decirse, de acuerdo con Baudrillard, que esto ha sido un error, pues si lo poético genera placer es porque rompe con las leyes fundamentales de la palabra humana. Descle esta perspectiva, existe una diferencia radical entre la actividad discursiva y los fenómenos poéticos puesto que los discursos responden a la ley del valor y no escapan al principio de contradicción, el cual es anulado en los textos poéticos. El poema, dice Baudrillard, más que un proceso lingüístico, es un proceso de intercambio simbólico; el poema se opone al discurso lingüístico, que es un proceso de acumulación, producción y distribución del lenguaje como valor. Lo poético "es irreductible al modo de signicicación, que no es sino el modo de producción de los valores clel lenguaje" (p. 224).

$\mathrm{Si}$ la poesía se define negativamente en oposición a la actividad de los discursos lingüísticos, positivamente puede definirse como proceso simbólico de intercambio que se instaura en el interior mismo de los signos y de los modelos comunicativos. Sin embargo, este proceso no es un proceso significante suplementario —como lo sería para LéviStrauss- añadido a la significación lingüística, sino que el intercambio simbólico rompe la finalidad de los modelos, la mediación del código y el ciclo consecutivo del valor. En consecuencia, la palabra poética volatiliza toda instancia social trascendente, todo cuerpo fijado del poder; por ello, la linguística no puede dar cuenta de esta operación de diseminación y disolución efectuada por la poesía, puesto que intenta situar lo poético en el campo del "querer decir", o sea en el campo de la producción de sentido.

Ante estas dos posiciones tan radicalmente opuestas, entre las que oscilan los estudios de la poética, queda la pregunta si la poesía significa o no significa; en el caso de responder afirmativamente, es decir, de concebir las obras poéticas como procesos productores de sentido, ¿cómo situarlas frente a los otros tipos de discursos? $Y$ esa pregunta conduce a otra: ¿cómo significan los textos poéticos? No podemos compartir la posición según la cual los textos poéticos significan de manera autónoma con respecto a los demás sistemas significantes; tampoco asumir la posición que se- 
ñala a los textos poéticos en una relación de pertenencia con otros procesos lingüísticos, o una mera coincidencia entre ellos. Pensamos que entre los fenómenos poéticos y los procesos de significación en general existen ciertas relaciones específicas, que no están claramente definidas. Las páginas que siguen constituyen una tentativa de planteamiento de esa relación.

3. Elementos para la definición del discurso. Toda definición de discurso tiene como punto de partida la dicotomía saussureana de langue y parole, ya sea para adherirse a ella o ya sea para criticarla. Jakobson, por su parte, llega a una definición de discurso por medio de un rodeo que consiste en la crítica de dicha dicotomía; para él, a causa de la intima relación entre lengua y habla, es imposible el estudio de la lengua sin hacer referencia a los discursos reales y concretos. $^{2}$

Jakobson define los discursos (produciones concretas de la lengua) descle dos perspectivas diferentes, una exclusivamente lingüistica y la otra con elementos extralingüísticos en juego. Sin embargo, no establece un punto de unión entre ambos acercamientos. Desde el punto de vista linguístico, todo discurso se caracteriza, según Jakobson, porque pone en funcionamiento el mecanismo de combinación de los signos, que pertenece al eje sintagmático y se distingue

2 Jakobson no acepta la dicotomia lengua/habla tal como la plantea Saussure pues piensa que requiere una aplicación cautelosa y no mecánica. Esta dicotomia se presenta como fenómeno complejo, pues "tras ella se esconden por lo menos tres antinomias independientes, a saber: en primer lugar la oposición entre norma de la lengua $y$ enunciado de la lengua, en segundo lugar la oposición entre el Ienguaje como bien supraindividual o social y el lenguaje como posesión individual o privada, $y$ en tercer lugar la oposición entre lo que el lenguaje tiene de unificador, comunicativo y centripeto, $y$ lo que tiene de individualizador, particularista y centrifugo" (Jakobson, 1962, p. 104). La lengua conticne tanto el impulso centrífugo como el centripeto, tanto el componente comunitario como el particularista, pero también, en tanto que bien social, encierra siempre tanto la "force unifiante" como "I'esprit particulariste" (Ibid.). En resumen, para Jakobson la producción de los mensajes no puede separarse de las estructuras lingüísticas, $y$ viceversa. 
del eje paradigmático, constitutivo más bien del código (clases y subclases de elementos). Así, la producción de los significados contextuales se origina por la combinación de los signos en los mensajes o discursos, mientras que los significados generales de los signos se refieren a la ordenación de los mismos en esas clases y subclases de los paradigmas lingüisticos. ${ }^{3}$

Desde la otra perspectiva, Jakobson clefine el discurso como un acto de comunicación; como tal, todo discurso hace intervenir, además del código, que es su factor más importante, a los protagonistas (emisor y receptor) y la situación especifica de enunciación, que llama contexto. En esas condiciones, la producción de significados, función primaria de todo acto discursivo, no es ajena a las actitudes de los sujetos, a su afectividad y a la situación espacio-temporal en la que se produce el discurso. En consecuencia, el discurso se distingue, ademís de por el mecanismo de la combinación y por su dependencia de un código, por los factores concretos que intervienen en la situación de enunciación.

A partir de los postulados de Jakobson es posible distinguir varios tipos de discurso, puesto que un mensaje no es nunca una realidad homogénea sino que realiza al mismo tiempo varias funciones, aunque hay una función predominante que es la que le otorga su unidad. Entre esos varios tipos, Jakobson establece una oposición básica entre discur-

3 Jakolsson clasifica los signilicados en dos niveles distintos: los invariantes y las variaciones. Entre los elementos invariantes incluye Ios significados gramaticales y los léxicos: "las palabras manifiestan dos clases visiblemente diferentes de valor semántico. Su significado gramatical obligatorio, concepto o grupo de conceptos relacionales que las palabras Ilevan consigo constantemente, queda completado en todas las palabras autónomas con un significado léxico" (Jakobson, 1972, p. 93). Las variaciones, por su parte, se refieren a los significados contextuales; si el significado general de un término se define por su pertenencia a una clase, el significado contextual se concibe como la aplicación de aquél a casos particulares: "en su significado general, todo nombre es un término genérico que se relaciona con todos los miembros de su clase o con todos los estadios de un todo dinámico. La aplicación contextual o situacional de estas características es una trans[ormación ampliamente aplicada" (Ibid., p. 94). 
sos poéticos y discursos referenciales. Los referenciales son los más cercanos a lo que se conoce como discurso en general, definido como aquel que se centra en el contenido del mensaje; los discursos poéticos, por el contrario, dirigen la atención del destinatario hacia el mensaje mismo. Esta definición del discurso poético tiene la ventaja de incluir la participación del receptor en la conformación del mensaje, pero también es una limitación al postular una separación tajante entre los discursos poéticos y los demás, separación que se expresa sobre todo en el postulado de Jakobson de la autonomia de la significación poćtica.

Tanto Jakobson como Benveniste han señalado la necesidad de la inclusión del estudio del discurso en la ciencia general del Ienguaje. Para Benveniste existen dos dominios o dos modalidades del sentido que se distinguen claramente, una que pertenece a la lengua y la otra al discurso. La lengua, dice, combina dos modos distintos de significancia, el semiótico y el semántico. Lo semiótico designa el modo propio del signo: un usuario de la lengua puede reconocer los signos que tienen un sentido de los que no lo tienen en su sistema comunicativo. Jo semántico designa el modo específico de los hechos discursivos, es decir, el funcionamiento de la lengua como productora de mensajes. El orden de lo semántico se identifica con el mundo de la enunciación y con el universo del discurso; la enunciación por $\mathrm{su}$ parte es "este poner a funcionar la lengua por un acto individual de utilización" (Benveniste 1977, p. 83).

El estudio de la enunciación debe pues, considerar tanto al acto mismo como a las situaciones en las que se realiza $y$ sus instrumentos formales. En primer lugar, el acto enunciativo pone en juego a un locutor que utiliza la lengua de una manera particular y toma frente a ella una posición. En tanto que realización individual, dice Benveniste, la enun-

4 Sobre la participación efectiva del receptor en la descodificación de los mensajes dice: "hablante y oyente son factores implícitos en todo acto de comunicación, en todo acto de habla. Ambos se convierten en parte del contenido del mensaje y esto es particularmente maniliesto en el caso del receptor, puesto que se ve obligado a interpretar el mensaje a causa de la ambigüedad" (Jakobson, 1961). 
ciación pucde definirse como un proceso de apropiación, y, por otra parte, supone siempre un receptor, es decir, es siempre un proceso dialógico, por lo que la presencia del otro es una de sus condiciones de existencia.5 Finalmente, en la enunciación la lengua se emplea en la expresión de una cierta relación con el mundo. La apropiación de la lengua tiene como una de sus funciones la necesidad de referir por medio del discurso.

Esta distinción entre lengua y discurso, o entre modo semiótico y modo semántico, ha tenido desarrollos en otros campos de estudio. Régine Robin, por ejemplo, toma esta distinción como base para la investigación de las formaciones discursivas en el campo de la historia (cf. Robin 1973), aunque critica la concepción individualista de Benveniste del acto enunciativo: éste, de la misma manera que Jakobson, considera que el sujeto de la enunciación manipula libremente los signos de la lengua para decir lo que quiere; por lo tanto, en esa postura está ausente la instancia ideológica en la producción de los mensajes.

El estudio del discurso tendría entonces que atender a las condiciones que hacen posible su producción o realización, condiciones que son tanto lingüísticas como extralingüisticas. Entre las segundas se incluyen entre otras los mar-

5 Hay algunas referencias en Jakobson sobre este aspecto, pero no constituye uno de sus temas centrales; dice, por ejemplo, que "el discurso individual no se da sin un intercambio. No hay emisor sin receptor [...]. En el lenguaje no existe la propiedad privada: todo está socializado" (1952, p. 21). La presencia del otro se encuentra más marcada en Voloshinov cuando dice, por ejemplo, "el acto de habla $o$, más exactamente, su producto, el enunciado, no puede en ninguna circunstancia ser considerado un fenómeno individual [...] el enunciatlo es un fenómeno social" (1976, p. 104); "la expresión-habla es determinada por las condiciones reales de un habla determinada, principalmente por su situación social inmediata" (Ibid., p. I07). Más precisamente, dice: "La palabra es un acto de caras. Está tan determinada tanto por quien la emite como por aquel para quien es emitida. Es el producto de la relación recíproca entre hablante y oyente, emisor y receptor. Cada palabra expresa el 'uno' en relación con el 'otro'. Yo me doy forma verbal clesde el punto de vista del otro $y$, en definitiva, desde el punto de vista de la comunidad a la que pertenezco." (Ibid., p. 108.) 
cos institucionales, Ios aparatos ideológicos, las representaciones implícitas o presupuestas, los efectos estratégicos perseguidos, las relaciones de fuerza, etcétera. $Y$ estas condiciones, dice Robin, no son simples circunstancias o contextos que limitan el discurso, sino elementos que lo constituyen $y$, como tales, exceden un estudio puramente lingüístico.

Otros teóricos del discurso tienden igualmente a acentuar las relaciones de las prácticas discursivas con ciertas realidades extralingüísticas, con el propósito de insertar el estudio de los discursos en una teoría de la sociedad. En este estudio, tanto en los trabajos de Pêcheux (1975) como en los de Foucault (1977) se introduce la noción de formación discursiva. A partir de una crítica de la noción de referente, Foucault cuestiona toda descripción del discurso como simple interrelación entre palabras y cosas; ${ }^{e}$ los discursos son para él prácticas sociales y como tales deben ser ubicadas en el conjunto de las prácticas de una sociedad determinada. Aquí Foucault señala lo que podríamos llamar la reglamentación social de los discursos: por medio de la noción de formación discursiva denomina un cierro orden o una cierta regularidad de las prácticas discursivas. ${ }^{7}$ Por ello la pro-

- Foucault propone que se prescinda de la noción de referente para aludir a las "cosas", es decir, a las entidades separadas y autónomas que se comunican a través clel discurso; con ello propone "sustituir el tesoro enigmático "de las cosast previas al discurso, por la formación regular de los objetos que sólo en él se dibujan. Definir esos objetos sin referencia al fondo de las cosas, sino refiriéndolos al conjunto de las reglas que permiten formarlos como objetos de un discurso y' constituyen así sus condiciones de aparición histórica" (Foucault 1977, pp. 73-79).

T.1 concepto de formación discursiva se describe por Foucault como sigue: "En el caso de que se pudiera describir, entre cierto numero de enunciados, semejante sistema de dispersión, en el caso de que entre los objetos, los tipos de enunciación, los conceptos, las clecciones temáticas, se pudiera definir una regularidad (un orden, correlaciones, posiciones en funcionamiento, transformaciones), se dirá, por convención, que se trata de una formación discursiva." Cada formación discursiva tiene sus propias reglas que son "las condiciones a que están sometidos los elementos de esa repartición (objetos, modalidades de enunciación, conceptos, elecciones temáticas), Las reglas de formación son condiciones de existencia (pero tambićn de coexistencia, de conservación, o de modificación y ce desaparición) 
ducción histórica de los discursos responde a reglas específicas y es la formación discursiva la que proporciona la configuración del espacio en el cual esas reglas son constantemente transformadas.

Pêcheux también define los discursos como prácticas sociales y con ello busca la relación entre las prácticas discursivas y las demás prácticas. Desde una posición marxista, Pêcheux postula una relación entre las prácticas discursivas y las ideológicas y concluye que los discursos son parte de la materialidad ideológica de las formaciones sociales. En otra palabras, las formaciones ideológicas conllevan como componentes una o varias formaciones discursivas, que determinan lo que puede y debe ser dicho en cada coyuntura histórica particular. ${ }^{8}$

Con la ubicación de las prácticas discursivas dentro del conjunto de las prácticas sociales, tanto Pêcheux como Foucault contribuyen con elementos nuevos para el estudio de las relaciones entre discurso y contexto social, y con ello posibilitan desarrollos en el estudio de la significación. Como muestra están los estudios de Verón (1974, 1978), quien define el discurso como proceso de significación y con ello afirma la necesidad de una teoría que explique su producción, que siempre es producto de un trabajo social. Para explicar esta producción, introduce la idea de

en una repartición discursiva determinada" (Foucault 1977, pp. 6263).

8 "Hablaremos de formación idcológica para caracterizar un elemento. (tal o cual aspecto de la lucha dentro de los aparatos) susceptible de intervenir como una fuerza enfrentada a otras fuerzas en la coyuntura icleológica caracteristica de una formación social en un momento daclo; cada formación ideológica constituyc así un complejo conjunto de actitudes $y$ de representaciones que no son ni individuales' ni 'universales', sino que se relacionan más o menos directamente con posiciones de clase en conflicto unas con otras" (Pêcheux 1975 , p. 26).

- La concepción de Verón de trabajo social es la siguiente: "Si consideramos el marco general de una teoría de la producción de sentido, este último aparece como resultado de un trabajo social (en una terminologia ligeramente diferente: como engendrada por las prácticas). Lo que se manifiesta entonces bajo la forma de cargas de sentido en las materias es el trabajo social" (Verón 1978, pp. 7.8). 
una pluralidad articulada de procesos productivos en el plano cultural:

la producción del sentido aparece organizada en diferentes prácticas. Cada una de ellas está sometida, en parte, a diferentes condiciones cstructurales en cuanto a la producción, la circulación y el consumo. En la medida que los grupos sociales que desarrollan estas diferentes prácticas no están relacionados del mismo modo con lia estructura de clases ( $y^{\prime}$ por lo tanto, con la estructura de poder), las condiciones históricas para el desarrollo de cada práctica productiva no son siempre las mismas (Verón 1974, p. 97).

De alli se deriva que los textos, lugares de manifestación de los sistemas sociales de producción de sentido, no sean objetos homogéneos sino plurales, puntos de convergencia de diversos sistemas. En cada texto es posible encontrar las huellas de esos distintos sistemas que contribuyen a su produción; entre ellos, Verón menciona las condiciones sociales de producción (ideologías, etcétera), el trabajo del inconsciente, la biografía del autor, las relaciones de poder.10 Más adelante tendremos ocasión de retomar estas consideraciones para referirnos a los textos artísticos.

Los trabajos de estos teóricos del discurso tienen la virtud de poner de manifiesto el funcionamiento de los discursos en la sociedad; sin embargo, su estudio se concentra en los aspectos contextuales (sociales, históricos, ideológicos) de la producción, y dedican mucho menos atención a la materialidad lingüística de estas prácticas. Un investiga-

10 La producción de sentido, dice Verón, aparece organizada en diferentes prácticas, cada una sometida a diferentes condiciones estructurales. Cada sociedad impone condiciones particulares a esa producción social de sentido. Lo que llamamos "la cultura" es el conjunto de campos que corresponden a las prácticas en las que consiste la producción de significación (Verón 1974, pp. 97-98). Estos sistemas sociales se manifiestan en textos, que son puntos de convergencia de sistemas diversos. Un texto, "como lugar de manifestación cle las fuerzas sociales, está lejos de ser un objeto homogéneo. Todo texto es susceptible de una multiplicidad de lecturas, es el punto de paso de varios sistemas diferentes $y$ heterogéneos de determinación" (Verón 1978, p. 12). 
dor que trata de conciliar ambos puntos de vista, aunque con una posición muy distinta, en Teun van Dijk: para él los estudios del discurso cleben tomar en cuenta ambos aspectos. En su libro Estructuras y funciones del discurso (1980), propone un acercamiento multidisciplinario: una teoría del discurso, dice, deben incluir la explicación de las funciones sociales que astumen los cliscursos en la comunicación; la base de los estudios del discurso debe incluir también una teoría de los contextos suciales donde se producen y comprenden los discursos rcales, "dada la afirmación trivial de que la lengua, el uso de la lengua y el discurso son fenómenos sociales" (van Dijk 1980, p. 106). El contexto social en el que se propone e interpreta un discurso es para él una abstracción de la situación social real en la que ocurre la comunicación; de allí que recurra a la noción de marco social que, de manera similar al marco cognoscitivo, es una estructura esquemática y ordenada de acciones sociales que operan como un todo unificado. Estos marcos formalizan no sólo los tipos de contextos en los que los cliscursos pueden ocurrir (públicos o privados, institucionales o no institucionales, etcétera), sino los papeles que asumen sus participantes; para ello, cada marco contiene un conjunto de convenciones, reglas, normas y estrategias que se actualizan por los participantes involucrados. El estudio de los contextos, añade van Dijk, debe realizarse en un campo més amplio, puesto que el discurso y la comunicación tienen propiedades diferentes en culturas diferentes: cada cultura selecciona los tipos de discurso y sus marcos sociales respectivos.

En vista de todo lo anterior, podemos concluir que el estudio del discurso no puede prescindir de la conceptualización de los contextos sociales y culturales en los que se producen y reciben; en este punto parecen coincidir todos los autores mencionados. Puede concebirse el discurso como acto comunicativo, como acto de enunciación, como proceso de significación o como interacción verbal, pero en todos los casos se requiere su ubicación en el todo social en el que se origina; dicho en otras palabras, se requiere atender la relación de lo discursivo con lo extralingüístico, sea esto 
una realidad referencial, otras prácticas sociales o los contextos culturales y de interacción verbal. La significación discursiva, como dice Benveniste, tiene siempre un carácter contextual y concreto. Contra esta característica se postula desde la perspectiva que veremos enseguida, la especificidad de los discursos literarios.

4. Proposición de la dicotomía discurso poético/discurso referencial. Una fuerte corriente en los estudios literarios define los discursos literarios o poéticos por oposición a los referenciales o discursos del lenguaje ordinario. Esta corriente se fundamenta en los trabajos de los formalistas rusos, quienes intentaron deslindar el objeto específico de los estudios literarios; ese objeto es para ellos la literariedad, es decir, las propiedades que hacen de una obra cualquiera una obra literaria.

El acercamiento formalista a las obras literarias se complica si nos situamos en la perspectiva de la significación. Parece casi imposible considerar la literatura como un conjunto de procesos de significación si se define la función poética -dominante en estos discursos- como una función autónoma, desligada de las otras funciones y contextos. En la poética de Jakobson coexisten dos puntos de vista irreductibles; por un lado, plantea la existencia de una función poética autónoma que define los textos poéticos y los separa de los demás textos; esta es la postura que rige sus ensayos de análisis de poesía y que trae como consecuencia que éstos se reduzcan a un deslinde de las formas y los sigrificados internos de los textos. Por otro lado, reconoce la existencia de las relaciones de la función poética con otras funciones en el interior de los textos poéticos; desde esta perspectiva no quedan limitadas las posibles relaciones de la poesia con las circunstancias del mundo.

No obstante, aunque esos dos puntos de vista coexisten, pensamos que el primer aspecto es el que predomina en la poética de Jakobson; es decir, que opta por la defensa de la autonomía de la función poética y por la separación entre los discursos poéticos y los demás tipos. $Y$ pensamos esto porque cuando Jakobson plantea la posibilidad de interac- 
ción de la poesía con los demás sistemas sociales, la piensa como una relación entre dos realidades irreductibles; en consecuencia la poesía aparece como radicalmente distinta de los procesos ideológicos o de los sueños, por ejemplo.

La posición que sustenta la autonomía radical de la función poética ha sido desarrollada por otros estudiosos de la literatura, que tampoco han superado la doble postura jakobsoniana, por lo que sus trabajos fluctúan entre postular una función poética autónoma y su ubicación en circunstancias y contextos sociales, pero sin integración. Este conflicto se manifiesta claramente en los escritos de Lotman y en los dos libros de retórica del Grupo $\mu$. Estos úitimos defienden la inmanencia semántica de los textos poéticos: un poema para ellos manifiesta un significado completo y constituye un modelo reducido del universo. Esta concepción es la base para postular un modelo semántico general y abstracto, aplicable a poemas de distintas épocas y regiones, modelo que distingue clos isotopías semánticas entre las cuales las figuras retóricas establecen la mediación. Este supuesto, sin embargo, les resulta insuficiente por lo que se ven obligadas a discutir la idea de una autonomía del texto. La definición misma de isotopia semántica implica tomar en consideración los contextos exteriores: todo análisis, señalan, supone la lectura, y en esa lectura influyen las determinaciones ideológicas y las fantasías del lector. Incluso el funcionamiento de las figuras es imposible de aprehender si no se toman en cuenta tanto las determinaciones contextuales como al lector, pues la construcción de la base sobre la que opera la desviación retórica es imposible sin las posiciones asumidas por el lector.

Una posición similar es la de Lotman, quien acepta un acercamiento interno y otro externo (extratextual) a la obra literaria, pero identifica su aspecto estético o artístico con las estructuras internas del texto, y con ello reproduce la dicotomía en Jakobson. Para Lotman, el análisis estuctural tiene su base en una concepción de la obra como totalidad orgánica; es la coherencia estructural lo que convierte un texto en objeto estético; en consecuencia, la significación poética se concibe como parte de esa estructura. 
También en Lotman se observa la coexistencia de una posición (la señalada en el párrafo anterior) con su opuesta; un texto poético es también para él un organismo en el que se vinculan diversos sistemas de significación; es un organismo no completo en sí mismo y en el que se actualizan al menos dos sistemas: el sistema de la lengua y el sistema literario de una época. ${ }^{11}$ Los textos poéticos se distinguen de los demás mensajes porque instauran una desviación frente a sus sistemas de base; y aquí también Lotman se ve obligado a incluir la perspectiva contextual en el análisis, pues la percepción de las desviaciones presupone tener en cuenta los contextos culturales en los que esos textos se generan. Es imposible deslindar los clementos nuevos si el lector no se sitúa en el marco de las tradiciones literarias en que el texto se basa.

5. Discusión de la dicotomia: los textos poéticos son discursos como los demís. Otro grupo de estudiosos de la poética no comparte la idea de oposición; para ellos, los textos poéticos están sujetos a las mismas reglas y restricciones válidas para toda la producción discursiva; con ello ponen en cuestión la noción de la literariedad, concebida como objeto de la poética: la literatura es una institución social y los hechos literarios sólo pueden verse a partir de las condiciones que posibilitan su producción y comprensión. Como cada sociedad o cada cultura posee normas institucionales diferentes, y esas normas son las que permiten reconocer un texto como literario, entonces el estatuto de las marcas poé-

11 Desde el punto de vista de Lotman, un texto "es una manifestación no de uno sino de al menos dos lenguajes. Consectentemente, ningún texto puede describirse adecuadamente en términos de un solo lenguaje. En este caso podemos hablar tanto de una codificación total por medio de un doble código, en la cual se percibe una u otra organización desde diferentes puntos de vista del lector, como de codificación total por algún cólligo dominante, con codificaciones locales de segundo, tercer, ctcétera, grados". E1 texto, en conclusión, "no es un contenedor pasivo, un mero receptáculo para un contenido insertado en él desde afuera, sino un generador. Pero esencia del proceso de generación está no sólo en la expansión de las estructuras, sino también, en un mayor grado, en su interacción" (Lotman 1979, p. 503). 
tico-textuales no es el mismo; es decir; no hay marca textual que sea poética en sí misma y fuera de las condiciones y contextos señalados.

Una defensora de esta perspectiva es M. L. Pratt (1977), quien incluye el estudio de la literatura en el campo de los estudios del discurso y el de los actos de lenguaje. Si hasta ahora, dice Pratt, las obras literarias se han separado de los mecanismos generales del discurso, ha sido por una concepción muy pobre del discurso, pues no hay tal cosa como el "discurso ordinario" o un discurso que cumpla funciones exclusivamente comunicativas y referenciales. Las funciones y propiedades adjuclicadas a las obras artísticas verbales valen muchas reces para los discursos no literarios, y esto puede observarse en el análisis de narraciones que no tienen por finalidad la creación artística. Así, no hay ninguna razón teórica que valide la separación entre enunciados literarios y enunciados no literarios, es decir -y esta sería la tesis de Pratt- no existen propiedades lingüísticas intrinsecas de la literatura.

En oposición a las corrientes formalistas y estructuralistas, Pratt propone un enfoque que permita describir los enunciados literarios en los mismos términos que se usan en otros tipos de enunciados ya que el discurso literario debe concebirse como un uso y no como una clase de lenguaje. Esto la conduce a tratar de establecer una relación entre los estudios literarios y la teoria de los actos de lenguaje; así, la obra literaria se concibe como una actividad comunicativa determinada por el contexto: la literatura es un contexto de lenguaje. Por lo tanto, la producción y comprensión de las obras literarias depende del conocimiento culturalmente compartido de las reglas, convenciones y expectativas que se ponen en juego cuando el lenguaje se usa en este contexto. Descle esta perspectiva, ya no se concibe que lo literario resida en el mensaje, sino en la particular disposición del emisor y del receptor con respecto al mensaje, lo cual está determinado por la situación comunicativa literaria. El estudio de Pratt se dirige precisamente a la descripción de esa situación comunicativa.

Como todos los cliscursos, el acto literario de lenguaje 
está sujeto a condiciones institucionales y su ocurrencia se da en contextos determinados, por lo tanto su descripción no puede darse fuera de ellos. Los procesos de producción y recepción de los textos implican toda una serie de mecanismos de selección de tal manera que cuando una obra llega al receptor, ha pasado por una selección, distribución y conservación, instancias todas ellas que desempeñan un papel central cuando se define la institución de la literatura.

El carácter discursivo e institucional de la literatura está presente también en los trabajos de van Dijk, para quien el discurso literario respeta todas las reglas textuales y gramaticales que operan en otros tipos de discursos; por ello, "un conocimiento de las posibles estructuras del uso de la lengua y del discurso en general desmitificará mucho de lo que se ha dicho ser típico de la literatura" (van Dijk 1980, p. 119). Oraciones agramaticales, significados y referencias ficticios son fenómenos no únicamente propios de los discursos literarios sino que están en todos los tipos de discurso.

Desde esta postura, si no existen cualidades lingüísticas intrínsecas de los discursos literarios, habría que definir el objeto propio de los estudios literarios desde fuera de los textos. La propuesta de van Dijk es que la literatura se define, en última instancia, en su contexto sociocultural: "las instituciones como las escuelas, las universidades, la crítica literaria, los libros de texto, las antologias, la historiografía literaria y las convenciones culturales de ciertas clases sociales o grupos establecerán, para cada período $\mathrm{y}$ cultura, lo que cuenta como discurso literario" (Ibid., p. 1.32). Por lo tanto, la admisión de un texto dentro del conjunto de "la literatura" dependerá de factores históricos y socioculturales cambiantes; para ello ciertas marcas textuales, consideradas como propias de "lo literario" en un momento histórico, pueden ser rechazadas en otro. En resumen, lo que cuenta como literatura se vincula siempre con procesos de recepción insertos en estructuras sociales determinadas. Al no separar las estructuras del discurso en general y las estructuras del discurso literario, van Dijk sostiene la posibilidad de la aplicación de la lingüística discursiva a las obras 
de arte verbales. Como en esta lingüística se busca siempre la coherencia de los discursos analizados, van Dijk insiste en que se haga lo mismo en los textos literarios..$^{12}$

En resumen, para quienes sostienen esta posición, el hecho literario es un modo específico de comunicación, es decir, un conjunto de convenciones aceptadas entre autores y lectores en sociedades históricamente dadas; la noción de la literariedad, por su parte, no se desecha sino simplemente se desplaza clel interior de los textos a las conductas de los sujetos en las sociedades en las que se usan los textos; por último hay que hacer notar que tampoco dejan de tomar en cuenta las características estructurales cle los textos literarios, puesto que interpretan las marcas o propiedades textuales en relación con la historia, la sociedad, su autor, sus lectores, etcétera.

6. La poesia: discurso y untidiscurso. En esta sección veremos una posición menos extendida que las anteriores, que postula que la poesía simultíneamente es discurso, porque no puede producirse fuera de los contextos socioculturales, ideológicos o institucionales, formalizados en determinados esquemas discursivos, pero que también es lo contrario al discurso, puesto que su acción no se reduce a la reproducción de dichos esquemas socialmente reglamentadas, sino que constituye un espacio donde esos esquemas se transfor-

12 Para van Dijk no hay propiedades textuales que, tomadas por sí solas, distingan a un texto como literario. Las formas lingüisticas no son condición necesaria ni suficiente para que un texto sea literario; las llamadas estructuras literarias no son literarias en si-mismas, sino que son propiedades obserradas en los textos literarios que por razones contextuales funcionan como literatura (van Dijk 1979, pp. 599). De allí su rechazo de la existencia de un lenguaje poético Y' cle la literariedad como objeto de la poética: "el objeto de la poética no es ni la obra de arte individual, ni el conjunto de textos literarios, ni la literariedad textual, sino un complejo sistema sociocultural, que incluye participantes con ciertos papeles y funciones (escritores, lectores, críticos, profesorcs, etcétera), las actividades de estos participantes [...] y los resultados objetivos de tales actividades (los discursos), y finalmente un número de reglas, convenciones, estrategias, etcótera), que determinan cstas activiclacles y los discursos que resultan de cllas" (Ibid., p. 602). 
man. Esto está en relación con la concepción del texto literario no como una entidad homogénea sino como algo plural.

Esta concepción de la poesía otorga un estatuto diferente a las marcas textuales: a diferencia de las dos posiciones de Jakobson (de acuerdo con la primera, ya mencionada, la marca textuales significan en sí mismas, son marcas de literariedad; de acuerdo con la segunda, toda marca debia leerse en relación con los contextos, tomando en cuenta la interrelación de funciones), al insistir en la heterogeneidad textual, postula que toda marca textual funciona a manera de articulación o embrague entre las diversas prácticas significantes presentes en el texto. Por otro lado, esta consideración de la poesía plantea ciertas preguntas, como las siguientes: si la poesia es al mismo tiempo discurso y antidiscurso, des ésta una cualidad exclusiva de los textos literarios o es más bien en este tipo de discurso donde es más evidente un funcionamiento propio de todo discurso? En el segundo caso, ¿debe entonces la ciencia del lenguaje incorporar conocimientos producidos en otros campos de estudio, como la teoría literaria, por ejemplo? Todorov habla de una nueva estética, que en varios sentidos se opone a la estética romántica; esta nueva estética se manifiesta en textos en los que se cuestiona sobre todo el postulado de unidad o de coherencia de la obra; en ellos se pone en práctica una concepción de la obra en la que está presente la voz del "otro". De acuerdo con Todorov, en rextos como los de Blanchot coexisten dos lenguajes, uno unitario y coherente, el otro infinito y heterogéneo; a este segundo lo llama "neutro" y lo define por una falta de referencia a la realidad. Lo neutro puede verse como una definición de la poesia, al menos de la poesía moderna, que es particularmente irreductible a toda acción unificadora y sólo podemos aprehenderla por medio de negaciones. Todo ello trasciende el romanticismo, el cual se funda en la identidad del individuo y asume una relación con el otro privilegiando Ia fusión de los contrarios; esta nueva visión de la poesía, por su parte descubre la diferencia del otro. La literatura sería, de esta manera, la forma de aprender a vivir esa relación no uni- 
taria, la posibilidad de aprehender al otro en su extrañeza radical (Todorov 1979).

Esa posición que señala Todorov para la poesía moderna, permea los planteamientos que concibe la poesía como discurso y como su opuesto. Stierle (1977) caracteriza la poesia a partir de la distinción entre discurso y texto; para hablar de discurso debe tenerse en cuenta que tanto la producción como la recepción dependen de un esquema discursivo, sujeto a un estatuto institucional; discurso y" "habla", en el sentido de Saussure, tampoco se identifican ya que el primero trasciencle la intención subjetiva del locutor. La identidad del discurso depende del esquema discursivo, orientado como esquema de la dimensión simbólica de los actos. Sin embargo, en su aspecto concreto, el discurso no se reduce a la manifestación del esquema que lo subyace puesto que entre el esquema y su realización pueden encontrarse discursos paralelos que ramificar el sentido por medio de conexiones y virtualidades relacionales implícitas. ${ }^{\mathbf{1 3}}$

Stierle se concentra en el poema lírico, que se caracteriza - contrariamente al cliscurso de carácter pragmático, fuertemente vinculado con su esquema--- por la transgresión de los esquemas. Aunque todo discurso tiene algo de antidiscurso - añade - la poesía lírica lleva esta tensión hasta el extremo, por lo que hace estallar su identidad como discurso. Esto no quiere decir que se deje a la arbitrariedad la conexión textual, asumida como negación del discurso, pero sí -y esto es lo que nos interesa destacar-. que la poesía está ligada a un esquema el cual impugna de una ma-

13 En palabras de Stierle: "Entre la identidad del discurso como dato a priori y la fideliclad de su concreción en el discurso mismo, existe una tensión que no podemos abolir completamente. Por un lado, no es sino ruptura que el texto deja ver ia identidad de un discurso, por otro, la identidad que se realiza en el discurso concreto no podrfa reducirse a la manifestación sin problema de un esquema discursivo [...]. La identidad del discurso depende esencialmente del hecho de que no es un acto nacido de una posición subjetiva, sino que procede de una praxis de la recepción que apunta al consenso [...]. El cliscurso no es cliscurso más que en la medida que remite al plano de fondo de un esquema cliscursivo preexistente" (Stierle 1977, pp. 426-427). 
nera específica (Stierle 1977, pp. 430-431). Todos los esquemas discursivos elementales son posibles esquemas de referencia para la transgresión lírica; por lo tanto, la poesía no es un género propio sino una manera especifica de transgredir un esquema genérico.

Si un discurso es una serie organizada de contextos de los cuales tenemos una percepción global, la transgresión se manifiesta de dos maneras: por la abolición (o por lo menos el cuestionamiento) de la linealidad, y por el entrecruzamiento de la complejidad textual: en la poesia la sucesividad ordenada de contextos se transforma en una simultaneidad problemática de contextos. ${ }^{14}$ Esta multiplicidad de los contextos en la poesía lírica se muestra esencialmente por medio del procedimiento de la metáfora, puesto que está vinculada con la cualidad poética de referir simultáneamente a múltiples contextos. La metáfora, entonces no es como a menudo se le califica, la figura de la identidad con apariencia de divergencia, sino la posibilidad de hacer perceptible en su diferencia lo que parece idéntico.

Cuando estamos ante una identidad discursiva problemática, es decir, ante un poema, el texto adquiere una función nueva: compensa esta identidad por medio de mecanismos de recurrencia; es decir, los rasgos yecurrentes textuales pueden funcionar como mecanismos de identilicación. Esta afirmación contrasta, como veremos, con la idea de Lajarte, para quien lás recurrencias lingüísticas del poema son mecanismos de transformación del discurso en antidiscurso.

Philippe de Lajarte, en un ensayo de análisis de un poema renacentista (Lajarte 19S0), parte también de la diferencia entre texto y discurso: el texto es un objeto lingüistico mientras que el discurso denota una realidad concreta que alude al uso de la lengua por un locutor determinado; el discurso es una práctica social con base lingüística regido

11 La transgresión del discurso, dice Stierle, tiene dos significaciones: "1) la abolición o, al menos, la puesta en cuestión de su linealidad; 2) el crucc de la complejidad de los contextos [...]. La sucesividad orclenada de contextos del discurso se transforma, cn la poesia lírica, en una simultaneidad problemática de contextos" (Stierle 1977 , p. 433). 
por un ritual y por unas normas. Este ensayo de análisis constituye una demostración de que un poema se escribe a partir de su adhesión a los esquemas poético-discursivos del momento de su producción, pero escapa a ellos y propone discursos opuestos. Con ello el autor da cuenta de la multiplicidad discursiva y de sus contradicciones.

Su tesis es que el poema no se reduce a los esquemas discursivos sobre Ios que se organiza el conjunto de sus significaciones y el sistema de su coherencia, sino que escapa a esa "discursividad" por medio de una serie de ordenamientos poéticos y connotaciones suplementarias y, más radicalmente, porque el trabajo propiamente discursivo aparece subvertido por fuerzas que operan en dirección contraria, como antidiscurso (Lajarte 1980, p. 438). En tanto que manifestación de un esquema discursivo, Lajarte deslinda tres elementos en el poema que analiza: a) las fuerzas ilocutivas del discurso; b) las presuposiciones axiológicas; ${ }^{15} \mathrm{y}$ c) la imagen que da de sí mismo el enunciador $y$, correlativamente, aquélla en la que invita a reconocerse al destinatario. De la interrelación entre estos elementos procede la identidad y la coherencia del poema. Pero además, aunque no de manera patente, existen en el poema analizado otros dos actos discursivos diferentes, que no sólo no se dejan integrar en el esquema discursivo sino que incluso 10 hacen estallar al inducir fuerzas, presupuestos semánticos y pragmáticos y una imagen del enunciador y del enunciatario inconciliables con las descritas por el elemento (c) del esquema. De esta manera, el antidiscurso opera la transformación de un modelo social del estatuto y de la función del poeta: el poema que Lajarte analiza, además de subvertir el ser del poeta, subvierte su hacer. ${ }^{16}$

15 Solre estos presupuestos axiológicos, dice Lajarte que "remiten a un presupuesto ideológico: a una cierta representación del estatuto y función del poeta en la sociedad, a un cierto canon de la aceptación literaria" (Lajarte 1980, p. 439).

10 Es interesante hacer notar el uso que hace Lajarte del análisis puramente formal (los paralelismos, por ejemplo): esos elementos no se separan del análisis puramente discursivo, pues los sistemas de correspondencias y paralelismos son más bien los elementos de base de un proceso global de transformación que va de un discurso a 
Puede observarse, entonces, una relación entre el proceso de simbolización externo del poema y el interno; a un discurso poético canónico, según el cual la poesía se inscribe en los circuitos comunicativos institucionalizados, se opone otro discurso que lo impugna. Pero lo interesante de la posición de Lajarte es su señalamiento de que, a este discurso poético externo, el antidiscurso no opone el recogimiento del verbo sobre sí mismo sino la inversión de las relaciones fijadas entre la poesia y el mundo. El discurso poético se convierte entonces en discurso sobre la función de la poesía y sobre el estatuto del poeta; es un discurso que no niega ni oculta la exterioridad que lo circunscribe $y$ determina.

A esta visión de la poesía queremos añadir la de Julia Kristeva. Aun cuando sus presupuestos teóricos sean divergentes, puede ser interesante una confrontación de puntos de vista ya que ambos coinciden en la visión del poema como un mecanismo en el cual se pone en funcionamiento al mismo tiempo un dispositivo regulador de la palabra $y$ una desorganización de ésta. Esta doble naturaleza del lenguaje poético pone en evidencia la escisión del sujeto sobre la cual se funda su posibilidad de predicación.

Kristeva menciona dos tendencias en la lingüística que incluye aspectos rechazados por el formalismo: la primera, que utiliza la teoría del inconsciente, impugna la tesis de la arbitrariedad del signo; la otra deslinda nuevas capas de la semiosis al proponer un sujeto de la enunciación. Estas dos tendencias forman, según Kristeva, los dos modos de un mismo proceso de significancia; el semiótico y el simbólico. El lenguaje llamado natural tolera diversas formas de articulación entre estos dos modos; su dialéctica es la que define los tipos de discursos. Para definir lo simbólico, Kristeva apela a Ios estudios de antropología de Mauss y Lévi-Strauss en los cuales lo simbólico es lo social ya que los lenguajes son los múltiples medios de regulación del cuerpo social, regulación $u$ orden simbólico que conduce al tema de la posicionalidad del sujeto y al planteamiento

otro; en el poema que analiza, es la transformación de las relaciones del sujeto nous con su destinatario y, conjuntamente, las relaciones de este sujeto con su propia identidad. 
de lo que ella llama "fase tétíca". El proceso de significancia, en el que convergen el modo semiótico y el simbólico, está estrechamente vinculado con la concepción del sujeto; si el sujeto es siempre semiótico y simbólico, todo proceso significante que produzca o en el que esté involucrado no será ni exclusivamente semiótico ni exclusivamente simbólico: desde la perspectiva del sujeto lo semiótico designa las pulsiones y sus articulaciones, mientras que lo simbólico pertenece al dominio de la significación, al dominio de las proposiciones y los juicios. La producción de juicios y proposiciones exige una posición definida del sujeto, posición que se estructura como un corte en el proceso de significancia en el cual se instauran como entidades diferentes el sujeto y sus objetos; a este corte le llama fase tética. Toda enunciación será tética porque exige la identificación del sujeto.

En toda práctica significante lo semiótico funciona como una transgresión de lo simbólico. La poesía, en tanto que práctica significante, ${ }^{17}$ combina los dos modos pero, de la misma manera que en las demás prácticas artísticas, esta combinación es cliferente que en las no artísticas, pues en estas últimas la negatividad de lo semiótico puede desintegrar la fase tética y conducir a la pérdida de la función simbólica, mientras que en las primeras la desintegración no puede ocurrir puesto que allí, al mismo tiempo que se conserva, se pone en cuestión el orden simbólico u orden de la cultura; sin embargo:

a través de temas, de ideologias, de significaciones sociales, el artista hace pasar en el orden simbólico una pulsión asocial toclavía no captada por lo tético. Que estal práctica se apoya a su vez contra el objeto producido y que, impugnadora.de toda suspensión, se erija a sí misma como sustituto de lo tético inicialmente impugnado, he ahí lo que da lugar

17 En ese orden sociosimbólico, dice Kristeva, la poesía tiene la función de "introducir, por medio de lo simbólico, to que lo trabaja, lo atraviesa y lo amenaza. Lo que ta teoría del inconsciente busca, el lenguaje poético lo practica en el interior del orden social: medio último de su mutación o de su subversión, condición de su supervivencia y de su revolución" (Kristeva 1974, p. 79). 
aI fetichismo $y^{\prime}$ al narcicismo estéticos que suplantan la teología (Kristeva 1974, p. 69).

El estudio de las prácticas artísticas, particularmente de la poesía, la conduce a considerar lo semiótico como inherente a lo simbólico; por lo tanto, se hace necesario considerar el funcionamiento semiótico en el interior de las prácticas significantes, además de la instancia simbólica. Sin embargo la descripción semiótica no debe fundarse en la escisión entre los dos modos de significancia, pues lo semiótico tiene que considerarse en relación con la posicionalidad del sujeto y con la enunciación. Esta dialéctica permite concebir las prácticas significantes como mecanismos desdoblados en forma asimétrica: ni se absolutiza lo tético erigiéndolo en prohibición teológica, ni se deniega cayendo en un irracionalismo atomizante; toda práctica significante evidencia una contradicción entre dos inconciliables que están separados pero no aislados.

Es en la literatura donde este funcionamiento se realiza de manera más explícita, y como ejemplo, Kristeva señala la poesia de Lautréamont y de Mallarmé, poesía que marca el fin de la poesía-delirio y el de su reverso, la sumisión al orden de la lógica. Asumir el proceso dialéctico del sujeto en la literatura implicó para estos poetas un rechazo de la poesía como huída y un combate contra el fetichismo del poema.

Si todo orden simbólico es social, reencontrar la palabra del sujeto supone entonces descender a las capas más profundas del orden social. Sin embargo, aunque en su tiempo son transgresiones, esas posturas funcionan como clasificaciones en el orden simbólico de la cultura. El poeta, concluye Kristeva, introduce la contradicción heterogénea dentro cie ese orden simbólico, inyecta la vehemencia pulsional en los códigos literarios fetichizados, pero sin destruir Jos límites del proceso.

7. Una concepción de la poesía en la obra de Octavio Paz. Quisiéramos terninar este trabajo con la exposición de las ideas de un poeta acerca de las relaciones entre poesía y 
lenguaje $y$ entre poesía y sentido. Los puntos de vista de Octavio Paz pueden adquirir otra base si los analizamos a la luz de las ideas sobre la concepción de la poesía como conjunción entre discurso y antidiscurso o como proceso dialéctico entre lo semiótico y lo simbólico. No es nuestra intención analizar la totalidad de las ideas de Paz acerca de la poesía ni hacer un estudio completo de sus posiciones contradictorias; se trata más bien de rescatar en su obra lo que, descle nuestro punto de vista, es lo más interesante y que es su definición de la poesía como crítica del lenguaje, como actividad que, sin dejar de ser lenguaje, muestra el revés de los signos.

Ya desde su primer trabajo importante sobre poética $(\mathrm{Paz}$ 1956, edición aumentada cle 1970), Paz aborda el tema de la relación entre poesía y comunicación o entre poesía y significación. Al intentar delimitar la naturaleza de las "palabras poéticas" dice que "sin dejar de ser instrumentos de significación y comunicación, se convierten en otra cosa" ( $p$. 22). Esta idea sobre la naturaleza dual de la palabra poética serí el eje central de lo que resta de este trabajo.

La relación entre poesía y comunicación o entre poesía y significación lo conduce directamente al problema de las relaciones entre poesía y lenguaje; como las palabras poéticas, dice, son "puertas que se abren a otro mundo de significados indecibles por el mero lenguaje" (Paz 1970, p. 22), por lo tanto, la aparición del lenguaje implica un rechazo a ese mundo de significados indecibles del poema.

La poesía es, según Paz, una forma peculiar de comunicación doncle el significado lingüistico coexiste con la imagen; esta ambivalencia se expresa en el siguiente pasaje: "Sin dejar de ser lenguaje — sentido y transmisión del sentido- el poema es algo que está más allá del lenguaje. Mas eso que está más allá del lenguaje sólo puede alcanzarse a través del lenguaje" (Ibid., p. 23).

La búsqueda de los vínculos y diferencias entre el funcionamiento del lenguaje y el de la poesía lleva a Paz a ciertos planteamientos en torno a las relaciones entre poesia e historia y entre poesía y sociedad. Si el lenguaje, en tanto 
que "habla", realiza un sistema de significaciones históricas, el poema "sin dejar de ser palabra e historia, trasciende la historia" (Ibid.). Sin embargo, Paz no sitúa el conflicto del poema dentro de la historia sino dentro del poema mismo. El poema va del sentido al sentido, es decir, de un significado histórico a otro, pero la operación poética no se limita a esto, sino que también efectúa una transmutación del tiempo y el senticlo históricos que consiste en dejar ver su falta, lo que ese lenguaje en su momento ha dejado de decirnos. Además, el acto de escritura tiene un modo polémico de asumir la historia: anula el tiempo y la sucesión al separarse de la situación concreta que le dio origen, pero a la misma vez se presenta como un acto no completo, como objeto que exige un acto de participación o de lectura, el cual se realiza siempre en un aquí $y$ un ahora, determinado e histórico. Dice:

La creación poética se inicia como violencia sobre el lenguaje. E1 primer acto de esta operación consiste en el desarraigo de las palabras. El poeta las arranca de sus conexiones y menesteres habituales: scparados del mundo informe del habla, los vocablos se vuelven únicos, como si acabasen de nacer. El segundo acto es el regreso de la palabra: el poema se convierte en objeto de participación ( $\mathrm{Paz} 1970, \mathrm{p} .38$ ).

La existencia misma del lenguaje implica su revés, que es una realidad no dicha que la imagen señala. E1 poema muestra este funcionamiento del lenguaje, la dualidad entre el mundo de la lengua, de las explicaciones y de la historia, y su más allá: la no significación, el reverso del habla. La imagen es para Paz el recurso del poeta cuando intenta expresar la terrible experiencia de lo que le rodea y de sí mismo; terrible porque es parte la experiencia de la división de su propio ser. Cuando comenta los presupuestos poéticos del surrealismo, Paz define la poesía como acto involuntario que "se produce siempre como ina negación del sujeto" (Ibid., p. 171); en consecuencia, si la poesía es pensamiento no dirigido, lo propiamente poético reside en los elementos inconscientes. Con ello, la "otredad" se des- 
plaza del poema al hombre mismo, que se ve a sí mismo como un sujeto no unitario. El poema es la posibilidad del acceso al enigma de la "otra voz" desconocida del hombre; como él mismo señala: "Desde esta perspectiva de incesante muerte y resurrección, de uniclad que se resuelve en "otreclad" para recomponerse en una nueva unidad, acaso sea posible penetrar en el sistema de la "otra voz" (Ibid., p. 176). En el epílogo a este libro, añadido en la edición de 1970 , el autor trata nuevamente el tema cle la "otredad", que define como "la percepción simultánea de que somos otros sin dejar de ser lo que somos y que, sin dejar de estar en donde estamos, nuestro verdadero ser está en otra parte" (Paz 1970, p. 266).

Este reconocimiento de la división o escisión del sujeto lo conduce a plantear de manera específica las relaciones de la poesía con la sociedad. Paz ve la poesía como la voz de los rebeldes, marginados o disidentes de la sociedad; pero aun así la relación entrañable entre el lenguaje social y el poema nunca se rompe. $Y$ a Paz le interesa encontrar ese vínculo o ese espacio en el que la poesía y la vida en sociedad se interpenetran: "no hay poesia sin sociedad, pero la manera de ser social de la poesía es contradictoria: afirma y niega simultáneamcnte al habla que es palabra social" $(1970$, p. 254). Los dos términos de la relación no pueden desvincularse aunque lo deseen, pues una sociedad sin poesía carecería de lenguaje, ya cue todos diríamos la misma cosa; una poesía sin sociedad es igualmente imposible pues sería como un poema $\sin$ autor, sin lector $y$ sin palabras.

También algunos poemas de $\mathrm{Paz}$ tienen como tema su concepción de la escritura; esto es evidente sobre todo en Ladera este (1960). En su "Carta a León Felipe", por ejemplo, expresa la idea de la escritura poética como "hueco en la escritura", como "hendidura entre una palabra y otra", o como "escribir sobre lo escrito lo no escrito":

\section{L'a escritura poética es}

El hueco de la escritura

Aprender a leer

En la escritura 
No huellas de lo que fuimos

Caminos

Hacia lo que somos

Lo dices en tu cartä

$$
\text { El poeta }
$$

Es el preguntón

El que dibuja la pregunta

$Y$ al dibujarla

Sobre el hoyo

La borra

Là poesía

Es la ruptura instantánea

Instantáneamente cicatrizada

Por la mirada de otros

Abierta de nuevo

Es la hendidura

$$
\begin{aligned}
& (\ldots) \\
& \text { La poesía }
\end{aligned}
$$

El cspacio

Entre una palabra y otra

Configuración del inacabamiento

("Carta a Lcón Felipe", Paz 1969, pp. 91-92).

En "Blanco", otro poema del mismo libro, Paz tematiza otra vez la relación entre palabra, mundo y poesia; esto constituye el inicio de una reflexión que se desarrollará en textos posteriores, sobre todo en El mono gramático (1974), donde empieza a cuestionarse el polo constituido por el mundo, puesto que allí el poeta pierde sus marcos de referencia y no logra vislumbrar límites claros entre el mundo y la palabra. La poesía expresa así esa dispersión de los signos, esa disolución de la palabra, que pensamos que podria interpretarse como una radicalización de la dialéctica señalada en El arco y la lira entre el lenguaje y el revés del lenguaje, entre el sujeto y su "otra voz". Sobre la relación palabra-mundo-poesía, el siguiente fragmento de "Blanco" nos da su versión:

Si el mundo es real

La palabra es irreal 
Si es real la palabra

El mundo

Es la grieta el resplandor el remolino No

Las desapariciones y las apariciones

El árbol de los nombres

Real irreal

Son palabras

Aire son nada

El habla

Irreal

Da realidad al silencio

Callar

Es un tejido del lenguaje

Sello

Silencio

Centelleo

En la frente

En los labios

Antes de evaporarse

Apariciones y' desapariciones

La realidad y sus resurrecciones

El silencio reposa en el habla.

$$
\text { (Paz 1969, p. 167). }
$$

La idea de la poesía como crítica del lenguaje es una idea recurrente en los escritos de Paz; en su colección de ensayos El signo y el garabato (1973) vuelve a ella, pero esta vez se concentra en la relación entre poesía y sentido. En este libro admite una relación entre el sentido y las cosas, que posteriormente será cuestionada en El mono gramático. La proposición inicial es que la poesia es siempre una alteración, una desviación lingüística, desviación creadora que produce un orden nuevo y distinto. Como la formación y uso del lenguaje implican la intervención de instancias sociales como las de la violencia de la razón y la del poder, en nuestros tiempos, que se caracterizan por la revuelta de las realidades, los poetas introducen en sus obras una crítica del lenguaje e incluso una crítica de la poesía misma. Con esta 
crítica, dice Paz, no se trata de hacer "una destrucción del lenguaje sino de una operación tendiente a revelar el revés del lenguaje, el otro lado de los signos" (1973. p. 28). Aquí también se encuentran algunos ecos de lo adelantado en $E l$ arco y la lira: la poesía "es irreductible a las ideas y a los sistemas. Es la otra voz. No la palabra de la historia ni la de la antihistoria sino la voz que, en la historia, dice siempre otra cosa" (1973, p. 165).

Al afirmar que la poesía es crítica del lenguaje pero sin eliminación del lenguaje, la voz que en la historia dice siempre otra cosa, Paz pone el acento en las determinaciones simbólicas e históricas del poema. Ningún texto, dice, es enteramente original, pues el lenguaje, su materia, es ya una traducción del mundo no verbal y de los demás textos de la cultura. También los estilos son colectivos y pasan de una lengua a otra; cada obra poética nace y vive en relación con otras obras escritas en la misma o en distintas lenguas.

Según Octavio Paz, el lenguaje permite al hombre la relación con las cosas del mundo. La ausencia de esta relación lleva a la evaporación del sentido y de las cosas mismas: "un mundo de puros significados es tan inhospitalario como un mundo de cosas $\sin$ sentido, sin nombres. El lenguaje vuelve habitable el mundo" (1973, p. 63). Esto último lo hace criticar el "poema-cosa", tan inalcanzable como el "poema-idea" de la poesía simbolista. Las palabras, material deI poema, son cosas, pero cosas que significan. La poesía no aniquila el polo del sentido pues esto equivaldría a acabar con el lenguaje. El poema muestra más bien la ambivaléncia del sentido: "es la hendidura por donde entramos en las cosas y la hendidura por doncle el ser se escapa de ellas" $(1978$, p. 103). Esta ambivalencia está presente en la dialéctica entre el lado sensible del poema y el lado inteligible; el sentido, dice Paz, mina sin cesar al poema; para defender su obra de la acción del sentido, los poetas acentúan el lado material del poema. El sentido, sin embargo. no puede ser anulado; lo que hacen los poetas es burlarse del sentido, dispersarlo, pulverizarlo, pero éste reaparece "integrado o en fragmentos vivos y coleando, como los trozos de la serpiente" (1973, p. 104). 
Opuestamente a las posiciones de El signo y el garabato, que tienden a acentuar la dependencia entre la poesía $y$ lenguaje, y por lo tanto entre poesía y sentido, en El mono gramálico (1974), texto hermano de Ladera este, Paz se interesa sobre toclo en la dispersión de los nombres y de las cosas a través del lenguaje de la poesia; se trata de la misma dialéctica pero con acentos distintos; en este libro el acento está en la dispersión, que se muestra en las formas: este texto se convierte a veces en trabalenguas en el cual no sabemos ni su principio ni su fin:

Ciertas realidades no se pueden enunciar pero, cito de memoria; "son aquello que se muestra en el lenguaje sin que el lenguaje lo enuncie". Son aquello que el lenguajc no dice y así dice. (Aquello que se muestra en cl lenguaje no es el silencio, que por definición no dice, ni aquello que diría el silencio si hablase si dejase de ser silencio, sino...) Aquello que se dice en el lenguaje sin que el lenguaje lo diga, es decir. (¿cs decir?) aquello que realmente se dice (aquello que entre una frase y otra, en una grieta que no es ni silencio ni vor, aparece) es aquello que el lenguaje calla (1974, pp. 26-27).

Hay en este texto una escisión entre poesía-lenguaje $y$ realidad. Lo no dicho del habla, la poesía, no es el otro lado de la realidad sino el otro lado del lenguaje. Los términos "lenguaje" y "realidad", distintos en sus otros textos, se funden en éste en una unidad irreductible: la realidad del hombre, parece decir, es la realidad del lenguaje. Poesía es "lo que tenemos en la punta de la lengua y se desvanece antes de ser dicho, el otro lado que no puede ser nombrado porque es lo contrario del nombre" (1974, p. 50).

La poesía en su radical operación busca la abolición, la disipación del sentido y esta ación redunda en una experiencia semejante a la de la locura, a la percepción de la cosa como cosa, más allá de los nombres, de su dimensión simbólica:

las frases configuran una presencia que se disipa, son la configuración de la abolición de la presencia, 
sí, es como si todas esas presencias tejidas por las configuraciones de los signos buscasen su abolición para que aparezcan aquellos árboles inaccesibles, inmersos en si mismos, no dichos, que están más allá del final de esta frase,

en el otro lado, allá donde unos ojos leen esto que escribo $y$, al leerlo, lo disipan (1974, p. 56).

El poeta, entonces, se coloca del lado de la no significación o del sin sentido. La poesía, crítica del lenguaje, adelgaza los nombres de las cosas hasta su evaporación o su transparencia. Gracias al poeta afirma $\mathrm{Paz}$, el mundo se queda sin nombres. Esta visión resulta enloquecedora para el hombre, pues

el camino de la escritura poética se resuelve en la abolición de la escritura: al final nos enfrenta a una realidad indecible [...] esa realidad visible sólo por la anulación del lenguaje en que consiste la operación poética es literalmente insoportable y enloquecedora $(1974$, p. 113). 18

Sin embargo, a pesar de lo radical de la experiencia, el lenguaje no puede ser finalmente abolido. El resultado es la copresencia en el poema de la significación y la no significación, del sentido y el sin sentido, del discurso y el antidiscurso.

Susana Matos Freire

Univcrsidad Interamericana

Pucrto Rico.

18 De acuerdo con Kristeva, cuando se pierden los marcos discursivos o marcos simbólicos de referencia, es decir, los marcos simbólicos de predicación de los sujetos, la experiencia poética se asemeja entonces a la experiencia de la locura. 
JEAN BAUDRILLARD, El intercambio simbólico y la muerte, Caracas, Monte Ávila, 1980.

Eamle Benveniste, Problemas de lingüistica general II, México, Siglo XXI, 1977.

Teun A. van D1Jk, "Advice on theoretical poetics", Poetics 8, nụm. 6, 1979.

$\longrightarrow$ Estructuras y funciones del discurso, México, Siglo XXI, 1980. Mrchel Foucault, Arqueologia del saber, México, Siglo XXI, 1977. Roman Jakobson, "El lenguaje común de antropólogos y lingüistas", 1961 (en Jakobson 1975).

-. "La lingüistica y la tcoría de la comunicación", 1961 (en Jakolsson 1975).

—-, "La estructura del fonema", 1962 (en Jakobson 1975).

-.., "La comunicacion verbal", 1972 (en Jakobson, Nuevos ensayos de lingüistica gencral, México, Siglo XXI, 1976).

_-, "Postscriptum", en Questions de poétique, París, Seuil, 1973.

—- Ensayos de lingüistica general, Barcelona, Seix Barral, 1975.

Julia Kristela, La revolution du langage poétique, Paris, Seuil, 1974. Philippe de LaJARTE, "L'antidiscours du poème", Poétique 44, 1980. Claude Lev-Strauss, Arte, lenguaje, etnología, México, Siglo XXI, 1968.

JURI Lotaran, "The future for structural poetics", Poetics 8, núm. 6, 1979.

Octavio PAz, El arco y la lira, México, FCE, 1956 (ed. aumentada de 1970).

—, Ladera esle, México, FCli, 1969.

—-, El mono gramático, Barcelona, Seix Barral, 1974.

—., El signo y el garabalo, México, Joaquín Mortiz, 1973.

Michel PÊCHeux, "Mises au point et perspectives à propos de l'analyse automatique du discours", Langages 37, 1975.

MARY Louise PratT, Toward a Spieech Act Theory' of Literary Discourse, Bloomington, Indiana University Press, 1977.

Regine Robin, Histoire et linguistique, París, Colin, 1973.

Karlheinz Stierle, "Identité du discours et transgression lirique", Poétique 32, 1977.

Tzvetan Todorov, "Reflections on Literature in Contemporary France", New Literary History X, núm. 3, 1979.

ELISEO VERón, "Acerca de la producción social del conocimiento", Lenguajes núm. 1, 1974. 1978.

VALENTí Voloshinov, El signo ideologico y la filosofia del lenguaje, Buenos Aires, Nueva Visión, 1976. 